\title{
Bile acid malabsorption in Crohn's disease and indications for its assessment using SeHCAT
}

\author{
H Nyhlin, M V Merrick, M A Eastwood
}

\begin{abstract}
Patients with Crohn's disease who suffer from longstanding diarrhoea that does not respond to conventional treatment pose a common clinical problem. Bile acid malabsorption is a possible cause, although its prevalence and clinical importance is unclear. This paper explores the clinical indications for referring patients with Crohn's disease for bile acid assessment and the extent of bile acid malabsorption in this selected group of patients. The selenium labelled bile acid SeHCAT was used to assess the effect of disease on the integrity of the enterohepatic circulation. Altogether $76 \%$ of the patients referred for bile acid assessment had longstanding diarrhoea that had not responded to conventional antidiarrhoeal treatment or an increase in steroid therapy as their sole or predominant symptom. Ninety per cent of patients with bowel resections, almost exclusively ileocaecal, had abnormal SeHCAT retention $(<5 \%$ at seven days). Twenty eight per cent of patients with Crohn's disease who had not undergone resection $28 \%$ had a SeHCAT retention $<5 \%$, signifying bile acid malabsorption. Nineteen of 22 patients given cholestyramine treatment subsequent to the SeHCAT test had a good symptomatic response. In conclusion, the prevalence of bile acid malabsorption in this selected group with Crohn's disease is sufficiently high to justify performing the SeHCAT test in order to separate the various differential diagnoses.

(Gut 1994; 35: 90-93)
\end{abstract}

Chronic or intermittent diarrhoea in adults may be an expression of various intestinal infections, inflammatory bowel disease, malabsorption, or functional disorders of the gastrointestinal system. Aqueous concentration of bile acids in the colon greater than $3 \mathrm{mM}$, especially of chenodeoxycholic or deoxycholic acids, whether due to disease, after resection of the terminal ileum, or idiopathic, may produce diarrhoea' as a consequence of a number of factors operating synergistically. These include increased epithelial permeability resulting from a detergent effect, stimulation of cyclic adenosine monophosphate (cAMP) in the colonic mucosa, nervous mechanisms, and/or increased colonic motility. The effect is exacerbated in the presence of pronounced steatorrhoea by certain metabolites of fatty acids produced by colonic bacteria. The prevalence and clinical importance of bile acid malabsorption in Crohn's disease is unclear. It is usual after resection of the terminal ileum, but according to some reports occurs in only a minority of unoperated patients. ${ }^{23}$ Never- theless, some authors have reported a high prevalence. ${ }^{45}$

Conventional methods of diagnosing diseases of the terminal ileum lack either sensitivity or specificity, or both. Radiological studies give no information about functional status, while the Schilling test is influenced by factors not connected with terminal ileal function, such as bacterial colonisation and pernicious anaemia. The cholyl-glycine $-1-{ }^{14} \mathrm{C}$ breath test measures terminal ileal function but is also influenced by bacterial contamination of the small bowel, the latter being the principal indication for performing this test. Direct measurement of faecal bile acids or of faecally excreted ${ }^{14} \mathrm{C}$-labelled conjugated bile acids are sensitive tests giving accurate measurements of the functional condition of the terminal ileum, but they are laborious, rely on faecal collections, and are not easily performed in patients with diarrhoea. The introduction of a selenium labelled bile acid - SeHCAT ${ }^{67}$ - provided a simple and reliable method of studying the enterohepatic circulation and the effect of diseases on its integrity. We report here our conclusions concerning its role in the clinical management of patients with Crohn's disease, after six years experience.

\section{Patients and methods}

Between 1983 and 198953 patients with Crohn's disease from two hospitals in Edinburgh that have specialist gastrointestinal facilities were investigated for bile acid malabsorption using SeHCAT. This test was not routinely available before 1983. There was no agreed protocol and patients were investigated only to the extent considered clinically appropriate by the clinician concerned. SeHCAT retention was measured only after other investigations had failed to account adequately for their refractory diarrhoea. Patients who had been referred for SeHCAT retention measurement were identified from the records of the Department of Nuclear Medicine and their notes were reviewed in 1990 by an independent physician (HN). Clinical details before and after investigation were available in all but two of the patients, allowing for assessment of the reasons for investigation, localisation of disease, and the implications of the SeHCAT results for treatment.

Twenty five of the patients had unoperated Crohn's disease and their symptoms had failed to respond adequately to conventional treatment. The distribution of disease is shown in Table I. Twenty six had previously undergone bowel resection for their Crohn's disease (22 ileocaecal, three colonic, and one limited ileal resection. Thirty one were female (mean age 39.8 years, range $16-72$ years) and 20 male (mean age 37.9 
years, range $16-60$ years). The mean duration of disease was $9 \cdot 6$ years (range $1-31$ years).

SeHCAT retention seven days after oral administration was measured using a shadowshield, whole body gamma counter, as previously described. ${ }^{8}$ Patients attended in the morning, having fasted overnight. After measurement of their background radioactivity levels (principally to ensure that they had not received other radioactive tracers), $40 \mathrm{kBq}$ of ${ }^{58} \mathrm{CoB}_{12}$ was administered orally with a drink of water. Thirty minutes later the patient's radioactivity level was counted again to obtain the $100 \%$ count rate value and also an estimate of the scattered counts from the cobalt in the selenium window. A total of $40 \mathrm{kBq}$ of ${ }^{75} \mathrm{SeHCAT}$ was then administered orally, and after a further wait of half an hour, a second measurement was made. The contribution of the scatter from ${ }^{58} \mathrm{Co}$ in the ${ }^{75} \mathrm{Se}$ window was calculated and subtracted. The patients returned one week later, when a further measurement was made of the radioactivity in both selenium and cobalt windows. The retention of each was expressed as a percentage of the initial administered activity.

The in vivo stability of both SeHCAT ${ }^{9}$ and ${ }^{58} \mathrm{CoB}_{12}$ are well established. Phanton measurements in our department indicate that the technique has a precision of better than $\pm 0.5 \%$ and a sensitivity of better than $1 \%$ of the administered activity.

\section{Results}

The most common indication for investigation (Table I) was the presence of diarrhoea that had failed to respond to conventional treatment and for which no adequate diagnosis had been made. Thirty one of the 51 patients $(76 \%)$ had diarrhoea as their predominant or only symptom and in most cases it was of lengthy duration (greater than three months) and had not responded to conventional antidiarrhoeal treatment or to an increase in steroid therapy. SeHCAT retention was less than $5 \%$ at seven days in 25 of these patients $(64 \%)$ and between $5 \%$ and $10 \%$ in three others (Tables II and III). In a further seven patients the diarrhoea had been controlled to some extent by treatment, but there was a suspicion that involvement of the terminal ileum was causing bile acid malabsorption and diarrhoea. Four of these patients had a normal barium follow through, in one this was not performed, and the two others had ileal strictures. Only one of the seven had a seven day

TABLE I Localisation in relation to the indication for investigation in 51 patients with Crohn's disease

\begin{tabular}{|c|c|c|c|c|}
\hline \multirow[b]{2}{*}{ Reasons for SeHCAT } & \multicolumn{3}{|c|}{ Localisation } & \multirow{2}{*}{$\begin{array}{l}\text { After resection } \\
\text { without } \\
\text { radiological } \\
\text { signs of } \\
\text { recurrence } \\
(n=13)\end{array}$} \\
\hline & $\begin{array}{l}\text { Small } \\
\text { intestinal } \\
+ \text { colonic } \\
(n=9)\end{array}$ & $\begin{array}{l}\text { Small } \\
\text { intestinal } \\
(n=15)\end{array}$ & $\begin{array}{l}\text { Colonic } \\
(n=14)\end{array}$ & \\
\hline Diarrhoea only $(n=39)$ & $8(4)$ & 11 & 9 & 11 \\
\hline $\begin{array}{l}\text { Diarrhoea and clinical suspicion of extension of } \\
\text { disease }(n=7)\end{array}$ & 1 & 1 & 5 & - \\
\hline $\begin{array}{l}\text { Diarrhoea plus other factors (incontinence (2), } \\
\text { weight loss (2), pre-op (1), flatulence ( } 2) \text {, routine } \\
\text { check up (1), perianal fistula }(1)\end{array}$ & 1 & 3 & 3 & 2 \\
\hline
\end{tabular}

TABLE II Localisation in relation to SeHCAT retention

\begin{tabular}{|c|c|c|c|c|}
\hline \multirow[b]{2}{*}{$\begin{array}{l}\text { SeHCAT } \\
\text { retention }\end{array}$} & \multicolumn{3}{|c|}{ Localisation } & \multirow{2}{*}{$\begin{array}{l}\text { After resection } \\
\text { without } \\
\text { radiological } \\
\text { signs of } \\
\text { recurrence } \\
(n=13)\end{array}$} \\
\hline & $\begin{array}{l}\text { Small } \\
\text { intestinal } \\
+ \text { colonic } \\
(n=9)\end{array}$ & $\begin{array}{l}\text { Small } \\
\text { intestinal } \\
(n=15)\end{array}$ & $\begin{array}{l}\text { Colonic } \\
(n=14)\end{array}$ & \\
\hline$<5 \%$ & 5 & 12 & 1 & 12 \\
\hline $5-10 \%$ & 1 & - & 2 & 1 \\
\hline$>10 \%$ & 3 & 3 & 11 & - \\
\hline
\end{tabular}

TABLE III SeHCAT results in relation to reason for investigation (all patients)

\begin{tabular}{llll}
\hline $\begin{array}{l}\text { SeHCAT } \\
\text { retention }\end{array}$ & $\begin{array}{l}\text { Diarrhoea } \\
\text { only }\end{array}$ & $\begin{array}{l}\text { Diarrhoea+ } \\
\text { extension of } \\
\text { disease }\end{array}$ & $\begin{array}{l}\text { Diarrhoea+ } \\
\text { miscellaneous }\end{array}$ \\
\hline$<5 \%$ & 25 & 1 & 4 \\
$5-10 \%$ & 3 & - & 1 \\
$>10 \%$ & 11 & 6 & 4 \\
\hline
\end{tabular}

TABLE IV Outcome of SeHCAT in Crohn's disease patients with and without bowel resection

\begin{tabular}{lll}
\hline SeHCAT retention & $\begin{array}{l}\text { Bowel resection } \\
(n=26)\end{array}$ & $\begin{array}{l}\text { No resection } \\
(n=25)\end{array}$ \\
\hline$<5 \%$ & 23 & 7 \\
$5-10 \%$ & 3 & 1 \\
$>10 \%$ & 3 & 17 \\
\hline
\end{tabular}

TABLE v Cholestyramine, effectiveness on symptoms in relation to $\mathrm{SeHCAT}$ results

\begin{tabular}{lll}
\hline SeHCAT retention & Effective & Not effective \\
\hline$<5 \%$ & 18 & 1 \\
$5-10 \%$ & - & 2 \\
$>10 \%$ & 1 & - \\
\hline
\end{tabular}

SeHCAT retention of less than $5 \%$; he also had ileal strictures on barium follow through. Nine patients who had severe symptoms in addition to their diarrhoea were referred for investigation of suspected bile acid malabsorption, including two whose predominating symptom was flatulence. Both the latter two patients had SeHCAT retention of less than $5 \%$ at seven days and responded symptomatically to cholestyramine.

Table IV summarises the SeHCAT results in relation to bowel resection. Twenty three of the 26 patients $(90 \%)$ with bowel resection had a SeHCAT retention of less than $5 \%$ at seven days. Twenty two of the 23 had undergone ileocaecal resection and one had had a limited ileal resection. The remaining three patients, with retentions of between $5 \%$ and $10 \%$, had undergone limited colonic resections. In the 25 patients with Crohn's disease who had not had bowel resection, seven $(28 \%)$ had a SeHCAT retention of less than $5 \%$ at seven days, in one retention was between $5 \%$ and $10 \%$, and $17(68 \%)$ had no evidence of bile acid malabsorption. Twenty two patients were given cholestyramine subsequent to the SeHCAT test, with a good symtomatic response in 19 (Table $\mathrm{V}$ ). $\mathrm{B}_{12}$ absorption is measured routinely in our protocol as an indicator of bacterial overgrowth. All the patients investigated had values within the normal range (retention $>23 \%$ ). 


\section{Discussion}

SeHCAT had been available for 10 years, but has been slow to obtain wide acceptance. Many of the initial studies concentrated on its use in patients with small bowel resections, in whom the $a$ priori probability of bile acid malabsorption is very high. In these patients it rarely added useful clinical information. Our experience in Edinburgh, where the test was developed and first employed, remains the largest yet reported, with over 1000 patients investigated for a variety of conditions. The accuracy and sensitivity of the SeHCAT test for detecting bile acid malabsorption is now well established. ${ }^{10} \mathrm{~A}$ particular advantage of this test over ${ }^{14} \mathrm{C}$ glycocholate and ${ }^{14} \mathrm{C}$ taurocholate is its ability to differentiate between malabsorption and colonisation, as SeHCAT is largely resistant to bacterial deconjugation and dehydroxylation. It is thus a pure marker of active transport of bile acids, which under most circumstances is the predominant mode of absorption and is limited to the terminal one metre of ileum, as opposed to passive diffusion, which occurs throughout the small and large bowel to an extent determined by the polarity of the particular bile acid or conjugate. Free bile acids are not present in the small intestine unless there is substantial colonisation with certain anaerobic bacteria. There is little passive diffusion oof the conjugates normally found. In particular the role of SeHCAT in the differential diagnosis of the diarrhoeal form of irritable bowel syndrome has recently been clarified. ${ }^{112}$ The presence of bile acid malabsorption in patients with a diseased but intact ileocaecal region could well be transient, changing with disease activity in the early phase of the disease, although this has not been documented. With time, however, and repeated relapses, fibrosis is likely to develop, resulting in a permanent impairment of bile acid absorption.

The purpose of the present study was, firstly, to explore the (de facto) clinical indications for referring patients with Crohn's disease for bile acid assessment in a centre where this test was familiar and secondly, to assess the extent of bile acid malabsorption among this selected group of patients. Some previous studies ${ }^{13-15}$ selected small series of patients with Crohn's disease on the presumption that these patients were likely to have bile acid malabsorption because of the common involvement of the absorptive sites of bile acids in the terminal ileum. In view of the patchy distribution of activity in Crohn's disease, however, it is not surprising that a poor correlation was found between the severity of bile acid malabsorption and radiological and other criteria of disease activity.

The three basic mechanisms of $B_{12}$ deficiency are well known: deficiency of intrinsic factor associated with pernicious anaemia, utilisation of $B_{12}$ by bacteria in a colonised small intestine, and loss of the specific transport sites due to disease or resection of the terminal ileum. The use of dual isotopes - free $B_{12}$ labelled with ${ }^{58} \mathrm{Co}$ and IF-B $B_{12}$ with ${ }^{57} \mathrm{Co}$ - allows simultaneous determination of the level of defect, whether gastric or absorptive. In this study only ${ }^{58} \mathrm{Co} \mathrm{B}_{12}$ was administered as interest was focused on ileal absorption. In bacterial overgrowth there is competition for uptake of vitamin $B_{12}$, reflected in a low ${ }^{58} \mathrm{CoB}_{12}$ retention. There is no single test that will detect all the organisms which may colonise the small bowel. In this study, no bacterial overgrowth could be shown. This may seem surprising at first glance as bacterial overgrowth is common in patients with Crohn's disease localised to the ileocaecal region. It may be explained synergistically by a number of factors. The most important is almost certainly selection. As is usual, clinical investigations were performed hierarchically, not inclusively, those for the commoner conditions taking precedence. Tests of colonisation thus preceded SeHCAT retention determination, which was not performed if a diagnosis had been obtained before reaching this level on the diagnostic 'tree'. Thus, patients with appreciable colonisation are likely to have been excluded. Secondly, the extent of small bowel involvement sufficient to cause bile acid malabsorption is commonly insufficient to give detectable $B_{12}$ malabsorption. ${ }^{12}$ Thirdly, there are important biological differences in behaviour and handling between SeHCAT and ${ }^{58} \mathrm{CoB}_{12}$. Whole body retention of ${ }^{58} \mathrm{CoB}_{12}$ represents largely the amount absorbed from a single passage across the ileum, and once absorbed it is not excreted in appreciable amounts. In contrast, after ileal absorption that has an efficiency of $95 \%-98 \%$, SeHCAT is carried to the liver, extracted, and secreted in the bile from which it re-enters the enterohepatic cycle. With this compound, therefore, the ileum is tested several times a day, while SeHCAT itself is effectively resistant to the microbiological deconjugation. This has the effect of amplifying a moderate absorptive defect which may remain undetected using the single-passage absorption of ${ }^{58} \mathrm{CoB}_{12}$.

This study was limited to a selected subgroup of patients with a high $a$ priori probability of bile acid malabsorption. They had all failed to respond to conventional treatment. Significant bile acid malabsorption was mainly found in operated patients and only in a relatively small number of unoperated patients with Crohn's disease. From the present series it is clear that SeHCAT, used selectively in patients with Crohn's disease to investigate longstanding diarrhoea that has failed to respond to conventional treatment, commonly identifies a treatable cause ( 39 of $51,76 \%$ ). Nineteen of the 25 patients with bile acid malabsorption had undergone bowel resection, leaving six patients who had not been operated on for their Crohn's disease, but who nevertheless had bile acid induced diarrhoea. Thus, although the cause of the diarrhoea in the 25 unoperated patients was presumed clinically to be bile acid malabsorption, in only seven $(23 \%)$ was malabsorption significant, indicating that this is not a common cause of longstanding diarrhoea in these patients. It is, however, causal in a significant minority who fail to respond to usual first line treatment. It is clear from these results that bile acid malabsorption occurs mainly in patients who have had an ileocaecal resection and is infrequently the cause of noticeable symptoms in unoperated patients. As patients were not routinely investigated after resection, even the operated group is a selected cohort in whom there was uncertainty whether 
the extent of resection was adequate to account for the symptoms. This underlines the importance of close cooperation between physicians and surgeons in the follow up of these patients.

When bile acid malabsorption has been diagnosed, a good therapeutic response is usually obtained to cholestyramine, and this is sometimes used as evidence of the disorder. By slowing large bowel transit, however, cholestyramine may act non-specifically. A therapeutic response in isolation is weak evidence only of bile acid malabsorption. The single patient who apparently responded to cholestyramine despite a normal SeHCAT may well have had a spontaneous cyclical change in clinical severity, while the failure of response to cholestyramine in one patient is thought to be due to non-compliance. In other patients the effect of cholestyramine on symptoms is impressive. It may well be that the case for a compliant medical regimen can be put forward more strongly and more confidently when a definite diagnosis of bile acid malabsorption has been made, and a clinically attractive method such as the SeHCAT test may serve this purpose.

\section{CONCLUSIONS}

Even though the study was limited to a selected subgroup of patients considered clinically to have a high a priori probability of bile acid malabsorption, significant malabsorption was found not only in a minority of unoperated patients with Crohn's disease who failed to respond to conventional therapy, but in a larger group of operated patients. In patients with Crohn's disease who have longstanding diarrhoea that has failed to respond to conventional treatment, SeHCAT commonly identifies a treatable cause ( 39 of $51,76 \%$ ).

1 Hofmann AF. The enterohepatic circulation of bile acids in health and disease. In: Sleisenger $M H$, Fordtran JS, eds. Gastrointestinal disease. London: WB Saunders, 1989.

2 Otte JJ, Andersen JR. The clinical value of faecal bile acid determination in patients with chronic diarrhoea of unknown origin. Scand f Gastroenterol 1986; 21: 585-8.

3 Scarpello JHB, Sladen GE. ${ }^{14} \mathrm{C}$ glycocholate test in Crohn's disease-its value in assessment and treatment. Gut 1977; 18: 736.

4 Farivar S, Fromm H, Schindler D, McJunkin B, Schmidt KW. Tests of bile acid and vitamin $\mathrm{B}$. Junkin B, Schmidt KW. Tests of bile acid and vitamin $\mathrm{B}_{12}$ metabolism

5 Van Blankenstein $M$, Hoyset $T$, Horchner P, Frenkel $M$ Wilson JHP. Faecal bile acid radioactivity a sensitive and relatively simple test for ileal dysfunction. Netherlands fournal of Medicine 1977; 20: 248-52.

6 Merrick MV, Eastwood MA, Anderson JR, Ross HMcL. Enterohepatic circulation in man of a gamma-emitting bileacid conjugate, 23-selena-25-homotaurocholate. $7 \mathrm{Nucl} \mathrm{Med}$ 1982; 23: 126-30.

7 Nyhlin H, Merrick MV, Eastwood MA, Brydon WG. Evaluation of ileal function using 23-selena-25-homotaurocholate, a gamma-labelled conjugated bile acid. Initial clinical assessgamma-labelled conjugated bile acid. Init.

8 Merrick MV, Eastwood MA, Ford MJ. Is bile acid malabsorption underdiagnosed? An evaluation of accuracy of diagnosis tion underdiagnosed? An evaluation of accuracy of diagnosis $665-8$.

9 Monks R, Boyd GS. Biologic stability of tauro-23- $\left[{ }^{75} \mathrm{Se}\right]$ selena-25-homocholic acid. $\mathcal{F}$ Nucl Med 1988; 25: 1411-8.

10 Merrick MV. Bile acid malabsorption. Clinical presentation and diagnosis. Dig Dis 1988; 6: 159-69.

11 Eastwood MA, Merrick MV. Bile acids in irritable bowe syndrome. In: Northfield TS, Jazrawi R. Bile acids in health and disease. Dordrecht: Kulver Academic, 1990: 267-73.

12 Williams AJK, Merrick MV, Eastwood MA. Idiopathic bile acid malabsorption - a review of clinical presentation, diagnosis and response to treatment. Gut 1991; 32: 1004-6.

13 Ferraris R, Jazrawi R, Bridges C, Northfield TS. Use of a labelled bile acid $\left({ }^{75}\right.$ SeHCAT) as a test of ileal function. labelled bile acid $\left({ }^{7} \mathrm{SeHCAT}\right)$ as a test of ileal function. Methods

14 Ordholm M, Pedersen JO, Arnfred T, Rodbro P, Thaysen EM. Evaluation of the applicability of the SeHCAT test in the investigation of patients with diarrhoea. Scand $\mathcal{f}$ Gastroenterol 1988; 23: 113-7.

15 Fagan EA, Chadwick VS, Baird IMcL. SeHCAT absorption: a simple test of ileal dysfunction. Digestion 1983; 26: 159-65.

16 Nyhlin H, Brydon WG, Danielsson A, Westerman S. Clinica application of a $\left({ }^{75} \mathrm{Se}\right)$-labelled bile acid for the investigation of terminal ileal function. Hepatogastroenterology 1984; 31 : 187-93. 